\section{Política pública e controle da violência: um estudo de caso na cidade de Salvador, Bahia, Brasil}

\author{
Public policy to control violence: a case study in \\ Salvador, Bahia State, Brazil
}

\author{
${ }^{1}$ Instituto de Saúde Coletiva, \\ Universidade Federal da \\ Bahia, Salvador, Brasil. \\ 2 Escola de Enfermagem, \\ Universidade Federal da \\ Bahia, Salvador, Brasil. \\ 3 Departamento de Saúde, \\ Universidade Estadual de \\ Feira de Santana, Feira de \\ Santana, Brasil. \\ Correspondência \\ J. S. Paim \\ Instituto de Saúde Coletiva \\ Universidade Federal da \\ Bahia. \\ Rua Basílio da Gama s/n, \\ Campus Universitário do \\ Canela, Salvador, BA \\ 40110-080, Brasil. \\ jairnil@ufba.br
}

\begin{abstract}
The aim of this study was to analyze the formulation and preliminary developments of a public policy to control violence in Salvador, Bahia State, Brazil. The study's theoretical reference was the cycle of public policies and contributions by "rational choice". The public policy analyzed here reached the first three levels of the political decision-making process: the issue was placed on the public agenda and was present in the discourse of public authorities, and a plan was drafted at the municipal level. The fact that various stakeholders and sectors were convened in the organizational structure proposed by the plan was not sufficient to encourage cooperation among individuals to act jointly in the plan's implementation. The mechanisms used to sensitize the stakeholders were not sufficient to mobilize them for the fight against violence under the proposed format. A public policymaking process should also consider the set of factors that encourage or constrain cooperation among individuals for collective action from the perspective of the common good.
\end{abstract}

Policy Making; Public Policies; Violence
Jairnilson Silva Paim 1

Heloniza Oliveira Gonçalves Costa 2

Ana Luiza Queiroz Vilasbôas ${ }^{3}$

\section{Introdução}

Pesquisas epidemiológicas têm produzido evidências que apontam a violência como um dos maiores problemas sociais com impacto na saúde dos brasileiros 1 . As chamadas causas externas representam a terceira causa de morte no Brasil, superadas apenas pelas doenças do aparelho circulatório e neoplasias (Departamento de Informática do SUS. Indicadores e dados básicos - Brasil - 2005; http:/ / tabnet.datasus.gov.br/cgi/ idb2005/matriz.htm). A violência apresenta-se de forma mais dramática nas áreas metropolitanas, atingindo especialmente as populações com piores condições de vida e jovens das periferias urbanas 2 . As taxas de homicídios para o grupo etário de 15 a 19 anos cresceram de 27,1 óbitos por 100 mil habitantes em 1991 para 40,5 em 20003.

Diversos estudos apontam as desigualdades sociais como um dos determinantes da magnitude e gravidade das violências 1,3,4 embora dada a complexidade do fenômeno da violência questionam a existência de relações de determinação unívocas e lineares ${ }^{2,4}$. A produção científica brasileira, desde a década de 80 , indica distintas abordagens e teorias para a compreensão e explicação das violências 5 . Ultimamente, constata-se uma abrangência maior das pesquisas, diversificando os enfoques teórico-metodológicos e os temas 6,7. A produção acadêmica dos cientistas sociais revela diferentes perspectivas de expli- 
cação e diversos campos temáticos: (a) reflexão sobre violência e seus significados; (b) representações sociais do crime, medo e violência; (c) quantificação da vitimização; (d) relações entre pobreza e violência; (e) criminalidade como objeto de política pública ${ }^{8}$.

No que pese a relevância desses estudos para o diagnóstico, explicação e compreensão do fenômeno, poucas são as iniciativas que analisam políticas públicas, tomando a violência como objeto de intervenção ${ }^{9}$ e escassas são as medidas para o controle pelos governos mediante planos, programas e projetos 10,11. Enquanto isso, as políticas de ajuste estrutural e a crise fiscal do Estado, associadas à exacerbação das desigualdades sociais 12 e à globalização do crime 13, têm trazido o debate sobre as políticas públicas e o papel do Estado.

No campo das ciências políticas é crescente a preocupação em entender por que e como o governo decide por fazer ou deixar de fazer alguma ação que repercutirá na vida dos cidadãos. Esta preocupação tem levado ao desenvolvimento de modelos de análise para o estudo do processo de formulação de políticas públicas. Souza 14 elaborou uma síntese desses modelos, classificandoos nos seguintes tópicos: (a) tipologia sobre política pública; (b) visão do incrementalismo; (c) ciclo da política pública; (d) modelo garbage can ou "lata de lixo"; (e) modelo da coalizão de defesa; (f) modelo de "arenas sociais"; (g) modelos influenciados pelo "novo gerencialismo público" e pelo ajuste fiscal. Das diversas definições e modelos identificados na revisão da literatura, a autora destacou os seguintes elementos: "A política pública permite distinguir entre o que o governo pretende fazer e o que, de fato, faz ...envolve vários atores e níveis de decisão, embora seja materializada através dos governos, e não necessariamente se restringe à participantes formais, já que os informais são também importantes ...é abrangente e não se limita a leis e regras ...é uma ação intencional, com objetivos a serem alcançados ...envolve processos subseqüentes após sua decisão e proposição, ou seja, ela implica também em implementação, execução e avaliação" 14 (p. 36).

Ao serem considerados esses elementos cumpre ressaltar que uma política pública não se limita à explicitação das intenções de governos, seja essa formal, traduzida em leis, planos ou projetos, seja informal, como declarações, discursos, dentre outros. Tais intenções, além de serem traduzidas em proposições e objetivos a serem alcançados, podem requerer mudanças na forma de atuação do governo. Nessa perspectiva, para classificar os atos de governo como uma política pública seria preciso verificar se, além da intenção formal de intervir sobre deter- minado problema, foram desencadeados os mecanismos necessários para assegurar a execução das propostas. Desse modo, os estudos sobre o "ciclo da política pública" 15,16,17 permitem analisar diferentes momentos: problematização, definição da agenda, formulação, implementação e avaliação.

Diante da oportunidade criada pela Prefeitura Municipal de Salvador, Estado da Bahia, Brasil, ao recorrer à colaboração da Universidade Federal da Bahia (UFBA) para responder ao problema da violência urbana 18 , surgiu o interesse de analisar o processo de formulação desta política e os passos iniciais para a implantação. A escassez de estudos sobre a formulação de políticas de controle da violência na literatura científica brasileira 5,6,9 reforçava a justificativa da investigação. Assim, o presente estudo tem como objetivo analisar a formulação e os desdobramentos preliminares de uma política pública para o controle da violência no Município de Salvador.

\section{Procedimentos teórico-metodológicos}

Foi realizado um estudo de caso tomando como objeto o Plano Intersetorial Modular de Ação para a Promoção da Paz e da Qualidade de Vida na Cidade do Salvador 18, proposto e elaborado por pesquisadores vinculados ao Instituto de Saúde Coletiva (ISC-UFBA). Trata-se de uma análise de política 17 , concentrando-se no processo de formulação e nos passos iniciais para sua implantação. Portanto, não se enquadra na análise de implantação ${ }^{19}$ nem na avaliação de políticas, ainda que esta possa ser realizada, segundo alguns autores 20,21, desde o momento da formulação, antes mesmo de produzir os resultados esperados.

Foram utilizados como referenciais teóricos o ciclo das políticas públicas 14,16,17 e o enfoque da "escolha racional" 22 . O policy cicle 15 possibilita revelar em detalhe o processo de formulação de uma política através de diferentes estágios: estabelecimento da agenda, definição do problema, formulação, implementação, avaliação e finalização. Correspondem a quatro momentos do processo de decisão na conformação de uma política pública: definição dos temas da agenda política; transformação da retórica dos decisores; alterações institucionais; e mudanças efetivas de atuação. Já o recurso ao enfoque da "escolha racional” 22 deveu-se à possibilidade de análise da cooperação para a ação coletiva. Ao levar em conta a necessidade de intervir nos múltiplos fatores da gênese das violências o plano sinalizava para o fato de que o enfrentamento deste problema demandaria uma ação articulada de múlti- 
plos setores e atores, ou seja: tratava-se de uma proposta que buscava alcançar a cooperação entre indivíduos e organizações para uma atuação conjunta na perspectiva de um bem comum - promoção da paz e qualidade de vida.

Do referencial policy cicle foram utilizadas as categorias processo de formulação e organização para a implantação da política, enquanto do enfoque da "escolha racional" foi incluída a categoria contexto externo. Esta é derivada da proposta de análise institucional 22 que reconhece fatores relacionados ao contexto externo (político, econômico e cultural), onde estão inseridos os espaços de tomada de decisões, como capazes de influenciarem as decisões e as ações dos atores ali envolvidos. A categoria processo de formulação foi caracterizada pelas seguintes variáveis: origem da iniciativa, formulação de proposições, elaboração de planos de ação, desenho estratégico e formalização da política. A categoria organização para a implantação da política foi representada pelas variáveis medidas organizativas e ações para implantação da política. O contexto externo, por sua vez, foi expresso pelas variáveis: apoio político, apoio financeiro e apoio da população (Tabela 1).

As estratégias utilizadas para a busca de evidências empíricas foram a análise documental e entrevistas semi-estruturadas com informantes-chave. Para a análise documental realizou-se consulta aos documentos e publicações oficiais, bem como aos registros existentes sobre o plano no ISC-UFBA e em órgãos da Prefeitura. Foram analisados documentos tais como: publicações no Diário Oficial do Município; planos; relatórios; atas e registros das reuniões; material de divulgação; matérias em jornais; registros dos eventos; e ofícios. A entrevista com informanteschave foi do tipo semi-estruturada, buscando a explicitação da sua experiência na formulação do plano, na implantação das primeiras ações, pontos de conflito, dinâmica dos trabalhos, caráter da política e a influência do contexto externo. Os critérios para seleção dos entrevistados foram: envolvimento desde a criação da iniciativa; ter sido responsável pela condução do plano; atuação na operacionalização das ações; ser dirigente do órgão municipal no qual o plano foi inserido; membros da instância de coordenação presentes desde o início da intervenção, com maior freqüência nas reuniões, e que assumiram funções de gerência; integrantes do ISCUFBA que participaram da elaboração do plano. Realizaram-se oito entrevistas com os seguintes informantes-chave: prefeito, um secretário, dois gestores, dois gerentes e dois pesquisadores.

Embora a pesquisa documental e as entrevistas que compuseram o conjunto da pesquisa con- templassem o período de 1999 a 2003 neste artigo utiliza-se apenas o material correspondente ao momento da formulação, com seus desdobramentos iniciais para a implantação (1999 a 2001).

\section{O processo de formulação}

Este processo diz respeito ao momento do ciclo da política no qual, após a problematização e a inclusão do problema na agenda pública, uma autoridade incorpora o tema no seu discurso e inicia um processo decisório sobre a questão. Nesse sentido, será apresentada a trajetória do plano desde a decisão do prefeito de tornar a violência urbana objeto de intervenção municipal até as primeiras medidas para a sua implantação.

\section{A origem da iniciativa}

A iniciativa desta política pública coube ao prefeito que buscou cooperação técnica junto à universidade. Na época justificou tal decisão por ter participado de uma reunião promovida por um organismo internacional com outros prefeitos de capitais, na qual indagava-se o que o município poderia fazer em relação à violência. Como não constatou resposta consistente a tal pergunta resolveu consultar especialistas no tema e iniciar uma intervenção. Esta iniciativa resultou na apresentação de um termo de referência elaborado por pesquisadores do ISC-UFBA, indicando alguns caminhos para responder à questão da violência no âmbito municipal, seguida de uma reunião com o prefeito e seus assessores quando foram discutidos a proposta de cooperação técnica, princípios e diretrizes do plano. Posteriormente, a Prefeitura firmou um convênio de

Tabela 1

Plano de análise: policy cicle e "escolha racional".

\begin{tabular}{ll}
\hline Categorias & Variáveis \\
\hline Processo de formulação da política & Origem da iniciativa \\
& Formulação de proposições \\
& Elaboração dos planos de ação \\
& Desenho estratégico \\
Organização para implantação da política & Formalização da política \\
& Medidas organizativas \\
Contexto externo para implantação da política & Apoio político \\
& Apoio financeiro \\
Apoio da população
\end{tabular}


cooperação técnica com a UFBA para a elaboração da proposta.

O plano decorreu do interesse do Prefeito em incluir na agenda municipal a questão da violência, mas havia a expectativa de produzir um instrumento capaz de captar recursos de outras esferas de governo e de fontes externas. Já entre os pesquisadores dedicados ao estudo da violência urbana tratava-se de uma oportunidade para intervir na realidade, mediante a elaboração de uma política pública, superando a fase diagnóstica dos estudos.

\section{O desenho da intervenção}

O plano considerou princípios definidos numa conferência internacional 23 e diretrizes do Ministério da Saúde 11 e do Ministério da Justiça 10. Reconhecia certas peculiaridades do poder municipal e realçava valores de paz, convivência saudável e qualidade de vida como componentes para a promoção da saúde e redução das violências. As diretrizes reconheciam as violências como problema de saúde pública, bem como a complexidade de sua determinação 5,7,8,12,13. O modelo explicativo construído sistematizava um conjunto de determinantes e condicionantes das violências nos planos estrutural e fenomênico 24 (Figura 1).

As respostas para esse problema através de políticas públicas implicariam a articulação de diversas iniciativas setoriais, levando em conta a governabilidade específica da Prefeitura sobre o problema e possíveis articulações com as esferas estadual e federal. O plano tinha como pressuposto a possibilidade de controlar violências, articulando um conjunto de ações, operações, projetos e programas, com a participação da comunidade e do poder público. Apresentava medidas inespecíficas de promoção da saúde e medidas específicas de controle de riscos e danos. Dispunha de intervenções mestras, representadas por projetos e operações voltados para a paz e qualidade de vida (ações educativas e culturais e espaços de convivência saudável); intervenções horizontais, mediante ação intersetorial dos distintos órgãos municipais potencialmente capazes de atuar na redução das violências; e intervenções verticais, compreendendo a articulação da Prefeitura com as esferas estadual e federal. Desse modo, era composto por 11 módulos: Educação para a Paz e Cidadania via Arte, Esporte e Lazer; Estudo e Trabalho; Implantação e Reforma de Equipamentos Urbanos com Desenvolvimento de Espaços de Convivência Saudável; Salvador Saudável; Ações Interinstitucionais de Prevenção e Controle de Violências e Acidentes e Assistência às Vítimas; Treinamentos; Investigações; Eventos; Sistema de
Informações das Violências e Acidentes; Sistema de Vigilância Epidemiológica de Homicídios; Dispositivos Legais e Procedimentos de Fiscalização no Âmbito do Poder Municipal 18.

Com base nesse desenho, cada módulo dispunha de um objetivo específico e explicitava as respectivas atividades, identificando os espaços de governabilidade municipal, estadual, federal e da sociedade civil organizada, com resultados a serem obtidos a curto, médio e longo prazos. A estrutura modular, inspirada no enfoque situacional do planejamento 24 foi justificada para permitir uma "autonomia relativa na sua implantação, de acordo com a disponibilidade de recursos e com a viabilidade institucional" 18 (p. 45). Os recursos necessários, a responsabilidade institucional e o prazo de execução das ações propostas em função dos objetivos dos módulos seriam definidos com a participação dos órgãos municipais pertinentes e das comunidades selecionadas para a intervenção.

\section{A formalização da política}

O plano foi aprovado e formalizado mediante o Decreto $n^{o} .12 .76825$ com a nomeação do gestor e dos membros da instância de coordenação. Além de institucionalizar essas estruturas, a autoridade municipal apoiou a realização de eventos para envolver dirigentes e técnicos de outros órgãos na sua implantação. Após a conclusão da versão preliminar do plano, foi realizado o primeiro seminário com a presença do prefeito, secretários municipais e técnicos de órgãos a serem envolvidos no trabalho. Resultou deste evento um relatório que destacava como pontos positivos da iniciativa a "vontade política", a integração das secretarias e a participação da comunidade. Foram enfatizados o desenho modular, a criação de oportunidades para discussão democrática, a valorização dos bairros e a "mentalidade a favor da paz". A intersetorialidade como meio de enfrentamento das violências, o reconhecimento das ações executados pela Prefeitura, o aproveitamento das estruturas existentes e os baixos custos foram também ressaltados na análise de viabilidade do plano.

\section{Organização para implantação}

O plano não previa a criação de uma estrutura municipal formalizada para gerenciá-lo. O desenho proposto ancorava-se na estrutura já existente, ou seja, o gabinete do prefeito. Propunha a instalação de uma instância de coordenação denominada Comitê Intersetorial (COIN) enquanto espaço de articulação entre os representantes 


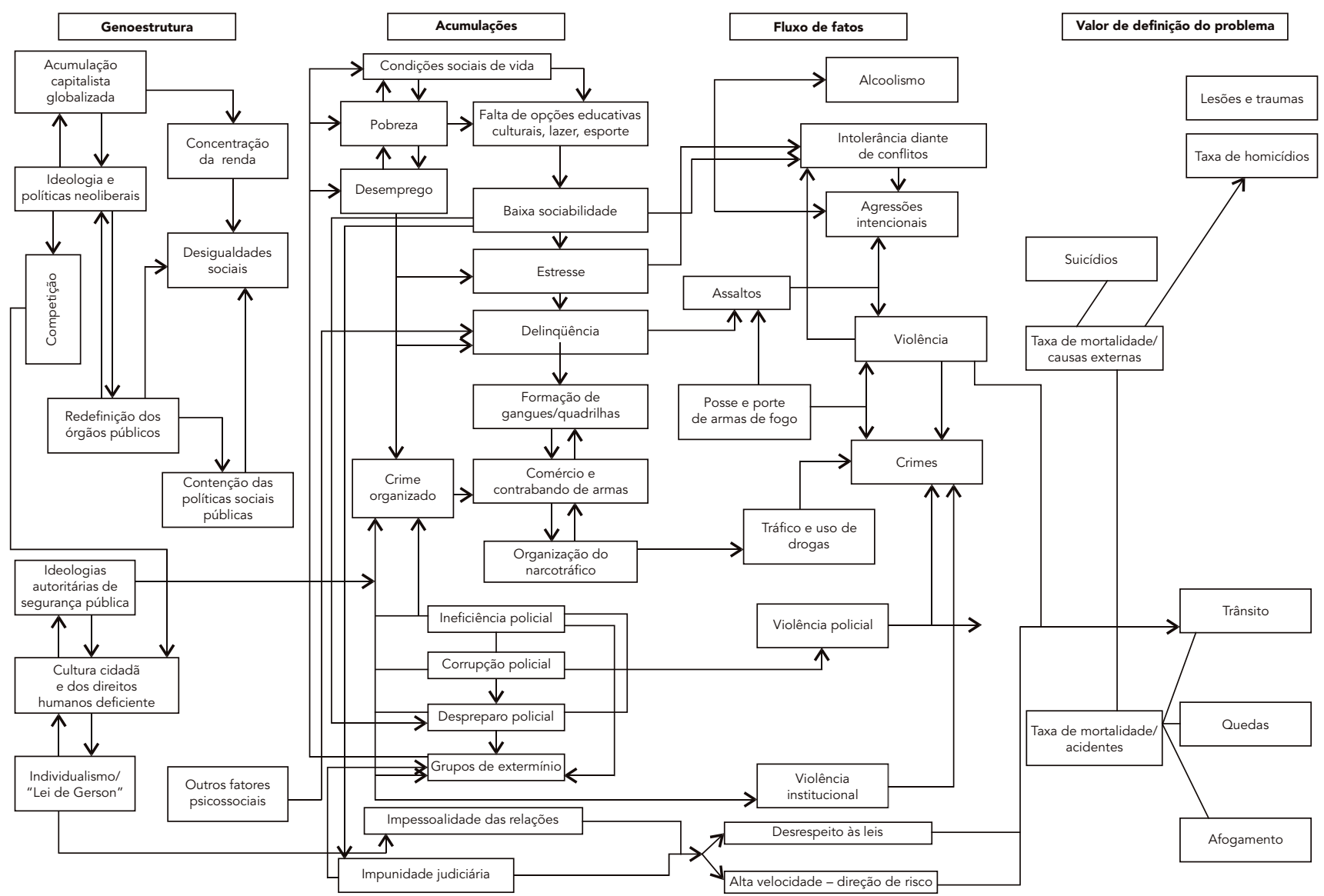

de 15 órgãos municipais diretamente envolvidos com as ações propostas no plano e a designação de um gestor ou "mediador estratégico", ligado diretamente ao gabinete do prefeito, com o papel de interlocutor entre a comunidade, os órgãos municipais e o prefeito 18 .

\section{Modelo organizacional}

O modelo organizacional priorizava uma organização com estruturas flexíveis tais como comitês, grupos de trabalho e força-tarefa, buscando o envolvimento de representantes dos diversos órgãos. As operações e atividades que integravam o modelo gerencial eram detalhadas em matrizes com a indicação da periodicidade, responsáveis, recursos necessários e indicadores para o acompanhamento e avaliação. O plano seria dirigido pelo prefeito através de um representante por ele nomeado (mediador estrégico), cuja função primordial seria articular os órgãos municipais da administração direta e indireta e as representações da sociedade civil nas áreas de intervenção. Seria imprescindível que tal mediador tivesse legitimidade junto às instâncias de poder (Câmara dos Vereadores e Secretarias Municipais) e possuísse experiência de trabalho junto à comunidade.

Além do COIN e do mediador estratégico, o modelo organizacional contava com o apoio de uma gerência de operações, responsável pelos módulos relacionados às intervenções mestras, ao sistema de informações, ao sistema de vigilância epidemiológica e aos eventos. A gerência de operações, composta por responsáveis de cada módulo, era subordinada ao mediador estratégico, podendo ser integrada por servidores municipais ou técnicos contratados pelo convênio. Ao lado do mediador estratégico estaria o 
COIN e os especialistas do ISC-UFBA que configurariam o seu suporte técnico, realizado sob a forma de consultoria de processo. No âmbito local, seria estimulada a formação do Conselho Comunitário visando assegurar a participação da comunidade e da Comissão Executiva Local, integrada por organizações que assinassem contrato de gestão com o poder público para execução das ações.

O plano explicitava que a mudança na forma de intervenção dar-se-ia pela articulação das ações, através do envolvimento das secretarias e órgãos do governo municipal num mesmo arranjo organizacional. Tratava-se de um modelo organizacional apoiado na liderança do prefeito e na sensibilização de dirigentes e técnicos dos diversos setores, considerando a intenção declarada do prefeito e o envolvimento dos secretários como condição para a implantação. Para a sensibilização dos atores propunham-se seminários, oficinas de trabalho, eventos, capacitação de pessoal, formação de lideranças, programas educativos e divulgação na mídia. Este modelo gerencial flexível e compatível com o caráter intersetorial e modular seria uma alternativa à burocracia convencional, permitindo que decisões e ações fluíssem com rapidez.

\section{O início da implantação da plano}

Selecionado o bairro por critérios epidemiológicos e realizadas as primeiras reuniões com representantes da comunidade, todos os membros do COIN e o mediador estratégico foram convidados a participar, enquanto alunos especiais, da disciplina Planificação de Saúde do ISC-UFBA. Os trabalhos de conclusão do curso privilegiaram o detalhamento dos módulos do plano, integrando equipes de alunos regulares com os participantes do plano.

Na primeira reunião do COIN, em julho de 2000, foram definidos os módulos prioritários para o início dos trabalhos. Neste semestre as reuniões eram quinzenais e depois semanais. As atas revelaram alguns temas recorrentes: articulação para as ações dos diversos órgãos com tentativas para incorporação do "sentimento de intersetorialidade na Prefeitura”; apoio ao COIN para tornar os seus membros mais seguros e superar a carência de identidade com o arranjo organizacional; discussão com o prefeito acerca da posição de poder do mediador estratégico diante das várias secretarias e órgãos municipais envolvidos no plano. Parte dessas dificuldades pode ser ilustrada com o seguinte depoimento:

"O plano era discutido em cada reunião do COIN e a partir daí seriam feitos os encaminhamentos. O representante no COIN de cada órgão ao qual tivesse afeita aquela discussão deveria levar para o seu órgão a demanda que estava sendo decidida para encaminhar a solução. Mas o que acontece é que nem todos os representantes, no COIN, eram pessoas encaminhadas ou escolhidas pelos secretários com o peso e a devida importância de estar participando daquele fórum" (Entrevistado 1).

Há registros de que embora estivesse ocorrendo o empenho e a participação de algumas secretarias, outras estavam ausentes no COIN e não assumiam os compromissos necessários para o desdobramento das ações.

“...As pessoas que eram representantes no COIN não tinham voz ativa nem representativa perante seus secretários. Então se elas saiam com uma decisão desse COIN, elas não eram ouvidas pelas suas secretarias" (Entrevistado 2).

As dificuldades de articulação para operacionalizar as ações foram referidas por quase todos os entrevistados, ora assinalando o escasso poder de decisão dos representantes, ora apontando o papel da burocracia na "proteção acústica do dirigente" 24:

“...Então foi muito difícil encontrar adeptos nas secretarias ... os secretários tinham uma burocracia muito grande para chegar até eles e eles precisavam autorizar que os seus representantes no COIN participassem e tivessem uma certa autonomia de decisão..." (Entrevistado 3).

Diante de tais problemas, continuaram as ações para sensibilização dos técnicos das secretarias e órgãos já integrantes do arranjo organizacional e de outros, de modo que novos representantes foram incorporados ao COIN. Observase, na trajetória de estruturação do arranjo que, mesmo com mudança e ampliação do número de componentes no COIN, o modelo organizacional e gerencial não conseguia fazer convergir para o mesmo espaço territorial selecionado as ações dos órgãos municipais no início da intervenção.

Ainda assim, foram realizados, com a participação da comunidade, eventos como feiras de saúde, gincanas, partidas de futebol, shows e cinemas em praças públicas, além de serem elaborados projetos para ampliação da unidade de saúde, melhoria do transporte público e contrução de escola no bairro. Entretanto, estas ações iniciais para a implantação do plano sofreram restrições políticas e financeiras.

\section{O contexto externo}

As variáveis do contexto externo que afetaram a implantação do plano estão relacionadas aos apoios político, financeiro e da população. O 
apoio político foi uma das variáveis que mais comprometeu o início da implantação na medida em que dirigentes indicaram representantes para o COIN que, na maioria dos casos, não tinham acesso direto aos secretários, nem ascensão hierárquica em relação aos setores técnicos. Desse modo, a composição do COIN contou com atores que, embora representando formalmente os secretários e dirigentes de órgãos municipais, não tinham a delegação para tomar decisões nem representavam os interesses ou preferências dos seus superiores. A falta de apoio financeiro é confirmada pela não alocação de recursos para a implantação, mesmo contando com a disposição de um vereador para incluir o plano no orçamento da Prefeitura. No caso do apoio da população, constata-se também certa insuficiência, pois representantes das comunidades ao participarem do espaço de tomada de decisão poderiam constituir grupos de pressão para fazer acontecer a política pública. Embora houvesse uma proposição no plano de que as atribuições dos Conselhos Comunitários deveriam ser estabelecidas de modo semelhante aos Conselhos de Saúde elas não foram definidas durante a formulação. Desse modo, as lideranças comunitárias, que exerceriam uma pressão direta para mobilizar os agentes e as agências do governo municipal, ficaram excluídas do processo, apenas facilitando a implantação das ações nos bairros. Portanto, pode-se inferir que não estava atribuído papel decisório relevante a tais conselhos face à localização periférica na estrutura decisória de atores que representariam a população beneficiária da política pública a ser implantada.

\section{Discussão}

O presente estudo, tendo como referências teóricas o policy cicle e o enfoque da "escolha racional”, procurou analisar o momento da formulação e as medidas iniciais para a sua implantação no âmbito municipal. Diante dos quatro níveis do processo de decisão política considerados no referencial teórico, pode-se afirmar que a política pública de controle da violência alcançou os três primeiros: o tema foi colocado na agenda pública, esteve presente no discurso de autoridades e foi elaborado um plano com realização de mudanças organizativas no aparelho de Estado no âmbito municipal. Ainda que certas ações tenham sido iniciadas, não é possível concluir quanto à efetivação desta política.

Embora o discurso dos entrevistados acentuasse o compromisso e a "vontade política" do prefeito para que o plano se efetivasse como po- lítica pública, não foi estabelecida uma rubrica de orçamento para assegurar a sua implantação, nem mobilizados recursos de poder para vencer a inércia institucional e as resistências políticas e burocráticas.

A inclusão do tema na agenda da Prefeitura e a elaboração do plano não resultaram da pressão direta de grupos organizados da sociedade para formular tal política. Mesmo que o tema da violência tenha sido problematizado na sociedade brasileira e alcançado o momento da construção da agenda não se constituía uma demanda política diante do poder municipal. Ainda que o prefeito demonstrasse sensibilidade para o problema, não se dispôs a gastar capital político no enfrentamento com seus auxiliares que não cooperavam, muitos deles indicados a partir de composições político-partidárias, nem a comprometer recursos orçamentários com a execução do plano. Sua expectativa reiterada em vários depoimentos de entrevistados era de captação de recursos externos, considerando o prestígio acadêmico da instituição universitária, e a possibilidade desta política pública tornar-se um case com acúmulos simbólicos para a gestão municipal.

A origem desta política não contemplou o envolvimento prévio do conjunto dos atores que estariam responsáveis pela sua implantação, apesar do seminário inicial e da formação do COIN. Foi, portanto, um arranjo criado não por iniciativa e mobilização de atores em busca de um bem comum ou de um bem público, mas por iniciativa da autoridade municipal. Configurouse, assim, um arranjo de origem exógena, isto é, criado e estruturado por atores externos ao grupo que comporia o modelo organizacional para implantar as ações. Isto significa que não se dispunha da garantia de rompimento da inércia dos atores para participar de uma ação coletiva. Este rompimento tem sido considerado condição necessária para a realização de ações conjuntas que visam o bem comum 22,26. Esses estudos indicam que os indivíduos tendem a cooperar para a ação coletiva quando se auto-organizam para demandar, usar ou produzir bens comuns.

Pela análise da formulação do plano inferese que os formuladores esperavam contar com a agregação dos indivíduos em torno de um mesmo arranjo organizacional para enfrentar o problema das violências. Esta seria suficiente para que a cooperação acontecesse na efetivação das ações, sem considerar a necessidade de incentivos para a cooperação. Assim, na organização para implantação do plano não foram previstas recompensas ou sanções para os participantes formais do arranjo. Isto sugere que não foi levada em conta a necessidade de criar mecanismos 
para minimizar os problemas da ação coletiva, comuns numa situação dessa natureza.

Além da criação do arranjo não se ter dado pela mobilização dos atores para a ação coletiva e da ausência de outros incentivos que estimulassem a cooperação entre eles, o plano trazia dificuldades adicionais para a articulação e cooperação em torno de um possível interesse comum: a multiplicidade dos objetivos e os distintos propósitos dos atores. Enquanto o prefeito encomendou um plano para captar recursos e colocar o controle das violências na agenda municipal, a proposta dos seus formuladores era imprimir um novo formato de intervenção governamental para tornar possível um impacto positivo sobre os determinantes e conseqüências desse agravo. Esta situação, ao lado dos interesses partidários distintos dos secretários municipais, colocava mais um obstáculo para a ação coletiva, na medida em que não havia espaço político de negociação para uma convergência de interesses. Vale salientar, também, que o formato de intervenção proposto implicava mudanças institucionais que exigiam, sobretudo, uma redistribuição de poder e o desenho de estratégias para a sua efetivação 27 .

Conseqüentemente, os mecanismos propostos para assegurar a coordenação visando a uma atuação integrada não levaram em conta que a cooperação não depende apenas da vontade dos indivíduos, mas tem a ver com o que, efetivamente, mobiliza os atores em torno de uma ação conjunta, minimiza os conflitos de interesses e a tendência racional dos indivíduos à não cooperar para a ação coletiva ${ }^{18}$. Desconsiderando esses aspectos implicados no agir coletivo para a provisão de um bem comum, os mecanismos previstos para articular os diversos setores e atores estavam apoiados, apenas, em dois pilares: no comando do prefeito, traduzido na vinculação direta do plano ao gabinete, com a explicitação de que o controle das violências era uma das prioridades da autoridade; e na sensibilização, formação e mobilização dos atores para uma cooperação voluntária. Esses pilares, embora necessários, não foram suficientes para contornar os problemas da ação coletiva inerentes a grandes grupos, pelo menos no momento inicial da implantação.

A proposta de intervenção de natureza intersetorial e multiorganizacional trazida pela universidade implicava custos político-institucionais elevados, tanto de implantação das ações como de mudanças na forma de intervenção do governo do município. No entanto, não foi estabelecida uma estrutura de recompensas e sanções a serem atribuídas às ações e aos seus resultados, que tornasse a relação custo-benefício mais favorável para os atores. Essas variáveis que apontam os custos e benefícios das ações parecem se constituir num dos elementos incluídos no cálculo que os indivíduos fazem para optar em cooperar ou não numa ação conjunta em função de um bem coletivo 18 .

Os resultados deste estudo reforçam a hipótese de que a agregação de distintos atores e setores numa estrutura organizacional não é suficiente para incentivar a cooperação entre os indivíduos para a ação coletiva. Demonstram ainda que os mecanismos de sensibilização utilizados para a implantação não asseguraram a mobilização de atores para o controle das violências, pelo menos nos passos iniciais para a implantação. Isto sugere que no processo de formulação de uma política pública deve-se levar em conta o conjunto de fatores que incentivam e constrangem a cooperação entre os indivíduos para uma ação coletiva na perspectiva do bem comum.

Os estudos desenvolvidos dentro da matriz teórica do neo-institucionalismo, mais particularmente da teoria da "escolha racional" 14,22,26, trazem elementos que contrapõem a suposição da cooperação contida no plano. Nesse sentido, têm buscado identificar e analisar as variáveis que caracterizam os espaços sociais onde os indivíduos interagem e que fatores internos e externos aos grupos podem potencializar ou impedir os esforços de grupos de indivíduos para traçar, criativa e construtivamente, soluções para seus problemas comuns, minimizando os problemas inerentes à ação coletiva.

Numa conjuntura em que a intersetorialidade e a ação solidária são incorporadas no discurso de governos para a promoção da saúde 28 , controle das violências 29 e redução das desigualdades sociais 30 , os resultados discutidos podem contribuir com a formulação de novas políticas públicas no sentido de evitar os problemas identificados neste estudo de caso. Contudo, a interpretação dos resultados exclusivamente à luz dos referenciais utilizados apresenta limites, na medida em que a análise do poder nas organizações que integram o aparelho de Estado requer elementos que ultrapassam o desenho de políticas e a esfera da cooperação entre indivíduos numa determinada arena de ação. No caso da política pública investigada, as forças internas e externas que apostavam na implantação do plano não tiveram as condições necessárias para obter a cooperação, nem mesmo recorrer à negociação, cooptação ou ao conflito aberto 24 com dirigentes e burocratas. Portanto, a política pública analisada requer estudos subseqüentes, com referenciais mais abrangentes e centrados nos momentos da implementação e da avaliação, contemplando mudanças efetivas na atuação do governo. 


\section{Resumo}

O estudo teve como objetivo analisar a formulação $e$ os desdobramentos preliminares de uma política pública voltada para o controle da violência em Salvador, Bahia, Brasil. O referencial teórico utilizado foi o do ciclo das políticas públicas e aportes da "escolha racional". A política pública analisada alcançou os três primeiros níveis do processo de decisão política: o tema foi colocado na agenda pública, esteve presente no discurso de autoridades, foi elaborado um plano no âmbito municipal. A agregação dos distintos atores e setores na estrutura organizacional proposta pelo plano não foi suficiente para incentivar a cooperação entre os indivíduos para agir, conjuntamente, na implantação do plano. Os mecanismos utilizados para sensibilização dos atores não foram suficientes para mobilizá-los para o combate à violência no formato proposto. O processo de formulação de uma política pública deve, também, levar em conta o conjunto de fatores que incentivam e constrangem a cooperação entre os indivíduos para uma ação coletiva na perspectiva do bem comum.

Formulação de Políticas; Políticas Públicas; Violência

\section{Colaboradores}

J. S. Paim e H. O. G. Costa participaram de todas as etapas da elaboração do artigo. A. L. Q. Vilasbôas realizou parte da coleta dos dados, da análise documental e revisou a versão final do artigo.

\section{Agradecimentos}

À bolsista de iniciação científica, Aletéa Barreto Medrado, que participou na coleta e sistematização dos dados para a análise documental.

\section{Referências}

1. Secretaria de Vigilância em Saúde, Ministério da Saúde. Impacto da violência na saúde dos brasileiros. Brasília: Ministério da Saúde; 2005.

2. Minayo MCS, Souza ER, organizadoras. Violência sob o olhar da saúde: a infrapolítica da contemporaneidade brasileira. Rio de Janeiro: Editora Fiocruz; 2003.

3. Assis SG, Deslandes SF, Santos NC. Violência na adolescência: sementes e frutos de uma sociedade desigual. In: Secretaria de Vigilância em Saúde, Ministério da Saúde, organizador. Impacto da violência na saúde dos brasileiros. Brasília: Ministério da Saúde; 2005. p. 79-115.

4. Macedo AC, Paim JS, Silva LMV, Costa MCN. Violência e desigualdade social: mortalidade por homicídios e condições de vida em Salvador, Brasil. Rev Saúde Pública 2001; 35:515-22.

5. Minayo MCS. Bibliografia comentada da produção científica brasileira sobre violência e saúde. Rio de Janeiro: Escola Nacional de Saúde Pública, Fundação Oswaldo Cruz; 1990.
6. Souza ER, Minayo MCS, Njaine K, Cruz AJM, Silva HB, Santos FCL, et al. Tendências da produção científica brasileira sobre violência e acidentes na década de 90. In: Minayo MCS, Souza ER, organizadoras. Violência sob o olhar da saúde: a infrapolítica da contemporaneidade brasileira. Rio de Janeiro: Editora Fiocruz; 2003. p. 49-81.

7. Adorno S. A criminalidade urbana violenta no Brasil: um recorte temático. BIB. Revista Brasileira de Informação Bibliográfica em Ciências Sociais 1993, 35:3-24.

8. Zaluar A. Um debate disperso: violência e crime no Brasil da redemocratização. São Paulo Perspect 1999; 13:3-17.

9. Minayo MCS, Deslandes SF, organizadoras. Análise diagnóstica da política nacional de saúde para redução de acidentes e violências. Rio de Janeiro: Editora Fiocruz; 2007.

10. Ministério da Justiça. Plano Nacional de Segurança Pública. http://www.mj.gov.br/acs/documentos/ pnsp/default.htm (acessado em 29/Jun/2000). 
11. Ministério da Saúde. Portaria GM no . 737. Aprova a Política Nacional de Redução da Morbimortalidade por Acidentes e Violências. Diário Oficial da União 2001; 16 mai.

12. Santos JVT. Introdução: por uma sociologia da conflitualidade. In: Santos JVT, organizador. Violência em tempo de globalização. São Paulo: Editora Hucitec; 1999. p. 11-39.

13. Zaluar A. A globalização do crime e os limites da explicação local. In: Santos JVT, organizador. Violência em tempo de globalização. São Paulo: Editora Hucitec; 1999. p. 91-100.

14. Souza C. Políticas públicas: uma revisão da literatura. Sociologias 2006; 8:20-45.

15. Kelly RM, Palumbo D. Theories of policy making. In: Hawkesworth M, Kogan M, editors. Encyclopedia of government and politics. London: Routledge; 1992. p. 644-55.

16. Meny I, Thoenig J-C. Politiques publiques. Paris: Presses Universitaires de France; 1989.

17. Viana ALA. Enfoques metodológicos em políticas públicas. In: Canesqui AM, organizador. Ciências sociais e saúde. São Paulo: Editora Hucitec/Rio de Janeiro: ABRASCO; 1997. p. 205-15.

18. Instituto de Saúde Coletiva, Universidade Federal da Bahia. Plano intersetorial e modular de ação para a promoção da paz e da qualidade de vida na cidade do Salvador. Salvador: Instituto de Saúde Coletiva, Universidade Federal da Bahia; 2000.

19. Denis JL, Champagne F. Análise da implantação de programas. In: Hartz ZMA, organizadora. Avaliação em saúde: dos modelos conceituais à prática na análise da implantação de programas. Rio de Janeiro: Editora Fiocruz; 1997. p. 49-88.

20. Bustamante F, Portales C. Evaluación de políticas y programas de salud. In: Cova DG, editor. Políticas de salud en América Latina: aspectos institucionales de su formulación, implementación y evaluación. San José: Centro Latinoamericano de Administración para el Desarrollo; 1988. p. 79-120.
21. Oxman G. Evaluación de políticas de salud. In: Cova DG, editor. Políticas de salud en América Latina: aspectos institucionales de su formulación, implementación y evaluación. San José: Centro Latinoamericano de Administración para el Desarrollo; 1988. p. 53-78.

22. Ostrom E. Governing the commons: the evolution of institutions for collective action. Cambridge: Cambridge University Press; 1990.

23. Organização Pan-Americana da Saúde. Declaração da Conferência Interamericana sobre Sociedade, Violência e Saúde. Boletim ABRASCO 1995; Ano XIII:2.

24. Matus C. Política, planejamento e governo. Brasília: Instituto de Pesquisa Econômica Aplicada; 1996. (Série IPEA, 143).

25. Prefeitura Municipal de Salvador. Decreto $\mathrm{n}^{\circ}$. 12.768 , de 10 de agosto de 2000. Constitui o Comitê Intersetorial do plano intersetorial modular de ação para a promoção da paz e da qualidade de vida na cidade do Salvador e dá outras providências. Diário Oficial do Município do Salvador 2000; 11 ago.

26. Costa HOG. Incentivos e constrangimentos à cooperação em arranjos organizacionais de combate à violência em Salvador [Tese de Doutorado]. Salvador: Escola de Administração, Universidade Federal da Bahia; 2005.

27. Levi M. Uma lógica da mudança institucional. Dados Rev Ciênc Sociais 1991; 34:79-99.

28. Ministério da Saúde. Portaria nº. 687, de 30 de março de 2006. Aprova a Política Nacional de Promoção da Saúde. Diário Oficial da União 2006; 31 mar.

29. Ministério da Justiça. Lei no .11 .530 , de 24 de outubro de 2007. Institui o Programa Nacional de Segurança Pública com Cidadania - PRONASCI e dá outras providências. Diário Oficial da União 2007; 25 out.

30. Comissão Nacional sobre Determinantes Sociais da Saúde. As causas sociais das iniqüidades em saúde no Brasil. Rio de Janeiro: Editora Fiocruz; 2008.

Recebido em 25/Mar/2008

Versão final reapresentada em 30/Jun/2008

Aprovado em 25/Ago/2008 